\title{
ENERGY CONSERVATION: POLICY ISSUES AND END-USE SCENARIOS OF SAVINGS POTENTIAL
}

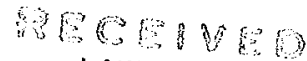 \\ A AWBEneE

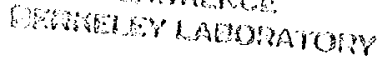 \\ JAN 121979 \\ monar ANIS \\ MOUMWNTS SERTES}

\section{PART I}

\section{SUMMARY}

\section{TWO-WEEK LOAN COPY}

This is a Library Circulating Copy which may be borrowed for two weeks. For a personal retention copy, call Tech. Info. Division, Ext. 6782

September 1978

Lawrence Berkeley Laboratory University of California, Berkeley 


\section{LEGAL NOTICE}

This report was prepared as an account of work sponsored by the United States Government. Neither the United States nor the Department of Energy, nor any of their employees, nor any of their contractors, subcontractors, or their employees, makes any warranty, express or implied, or assumes any legal liability or responsibility for the accuracy, completeness or usefulness of any information,apparatus, product or process disclosed, or represents that its use would not infringe privately owned rights.

Printed in the United States of America

Available from

National Technical Information Service

U. S. Department of Commerce

5285 Port Royal Road

Springfield, VA 22161

Price: Printed Copy, \$ 4.50 Domestic; \$ 9.00 Foreign

Microfiche, \$3.00 Domestic; \$4.50 Foreign 
ENERGY CONSERVATION: POLICY ISSUES

AND ENDOUSE SCENARIOS OF

SAVINGS POTENTIAL

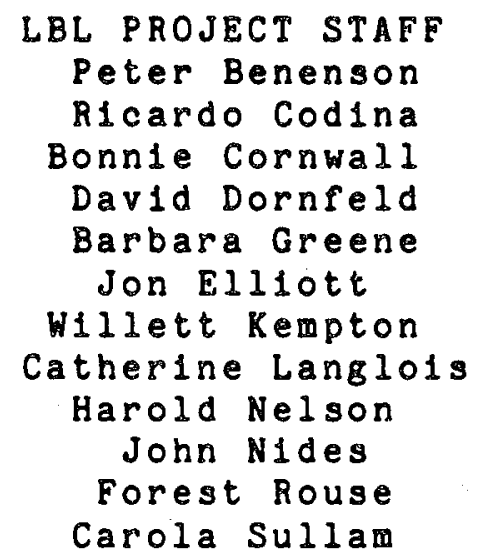

CONSULTANTS

Richard Barnes

Dow Chemical, USA

Norman M. Bradburn

Department of Behavioral Sciences

University of Chicago

Lawrence Berkeley Laboratory University of Californda, Berkeley

September 1978

Prepared for the U.S. Departwent of Energy under Contract W-7405-ENG-48 submitted to Dr. Clark Bullard Director, office of Conservation and Advanced Energy Systems Policy

U.S. Department of Energy 
TABLE OP COATEMTS

PART

1. SUAMARI

2. TRADEORES OF MOKICIPAL SOLID MASTE PROCESSIHG ALTERMATIVES

1) Roononica of Gerbage Collection

2) Mocbanioal ra. Howe Separation of Reoyolables

3. POLICI BARRIERS AND IVYESTMEAT DBCISIONS IM IMDUSTRY

1) Methodology for the Identification of Potential Barriers to Industrial Bnergy Conservation

2) The Procos of Industrial Investinent Decisionank$1 \mathrm{ng}$

4. BHERGI BFPICIBHT RECREATIOHAL TRAVBL

1) In Inforation Syater to Prowote Energy Bfricient Reoreational Travel

2) Heoreational Travel: Nat1onal Importance and Ind1v1dual Dec1810n-aking

5. BNERGI BFEICIENT BUILDINGS

1) The Causeg of Litigation Againat Bnergy Conservation Building Codes

2) Description of the Buliding Process

6. BND-USE BNERGI CONSERVATION DATA BASB AND SCEMARIOS

1) Hesidential

2) Corareis

3) Transportation

4) Industris 1 


\section{TORBYORD}

The onolosed work l based upon our provious research during this fisel year. oontalaed in conatruction of Bnergy Conaervation Soenar108: Intorlaport of Hork in Progres", LBL 7834, JuBe 1978. Tho cocus of our current work was deternined in conaultetion with the Director and ataff of the Conservation and Adranoed Bnergy syatens Polloy offloe, DOB, Polloulne their rovis of our interin report. Lt that polnt wo gred on averal guidelines for our subsequent work:

1. Tako wollatio viow of nergy conervation pol1c1er by dooribing tho orerall gyaten in which they aro 1 a 1 ancont:

2. Provido angtical toola and sulficlontly disaggrogatod dat baso that oa bo adaptod to anwer a variety of que tions by the users;

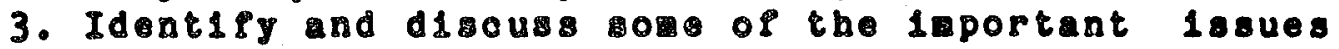
behind uocessful nergy conservation pol10y;

4. Devedop a energ conservition policy in depth.

In addition to tho so reldar, we relected five subjects to Investigato.

1. Recjcling: in andys of the energy, economic, and environontel tradeolpg between landfill and combined prograt of raburce recovery and onergy beneration frok wate.

2. Indugirial Dec1sion-Making: a gethodology to 1dent1fy potential barriers to nergy conservation by anajyzing how a conservation asure's attributes interact with the characteristics of an industrial subsector.

3. Recrational Travi: Inforation strateg1es to effect odal obift to public transit for the recrotiond trip.

4. Residential and Comercial Buldalnga: an examation of oourt cos agast new energy efficient buliding codes and susgestion for avolding future 11t1BQ10n.

5. End Us Bnergy Conservation Data Base: completion of anergy congovation gonarios by calculating the onery conservation potential of apecific measures applicable to pastioular end uses.

Our cuprent work roults Prop the epplication of the overall guldeling to tho bove ubjocta. For oxampe, we have doscribed the gatem in whioh ach polloy or $18 s u$ is set by the use of lowohart and oooompanying text. In

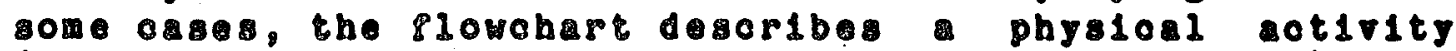
(constructing buldolng or poyoling mato aterials). In other case, 14 describos doolsion-making process (Industrial lavertant or tranaportation nodal cholos). 
We have provided dsaggregated quantitat1ve data wherever they are relevant--recycling, recreational travel, industrial decision-making, and the end use scenarios. We have discussed several policy lssues for which these data are relevant :

1. What are the tradeoffs between landfill and combined resource recovery-garbage to energy programs. 2. What are the stated and underly1ng causes of law suits against bullding codes.

3. How can the present modal distribution that is heavily weighted toward the atomobile be shifted to public transit for the recreational trip.

4. What are the conditions that present barriers to energy conservation investment in the industrial sector.

In the case of recreational travel, we have developed a speciflc policy to link national parks with public transit.

Our results for ach of the five subjects are bound separately; the subjects do not readily lend themselves to integration and the DOE starf did not think it would be useful to attempt one. We have issued a separate summary volume for those who want an overview of all the subjects investigated. 


\section{ACKNOWLEDGMENTS}

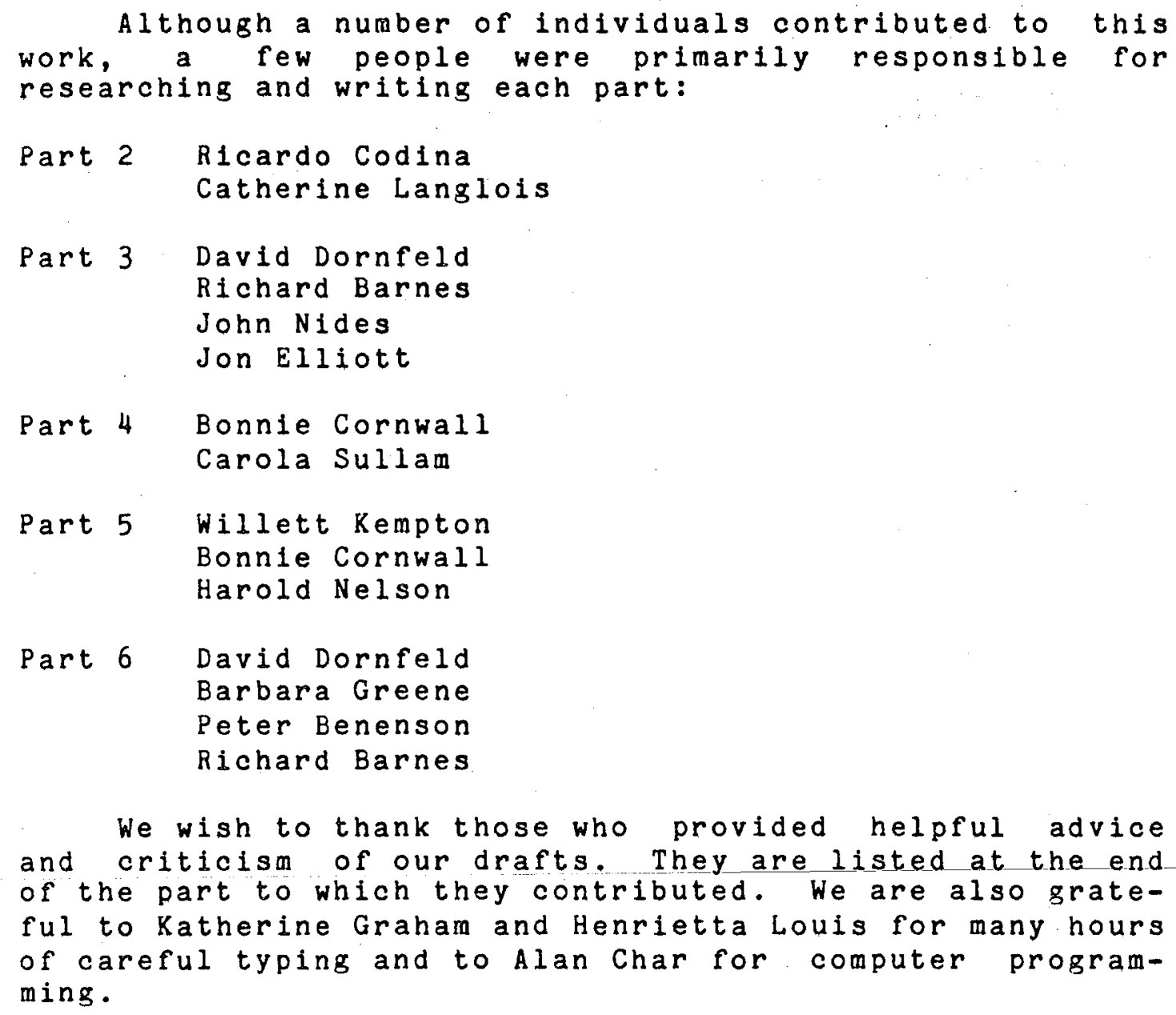


viji

TABLE OF CONTENTS

page

ENERGY EFFICIENT BUILDINGS

ENERGY EFFICIENT RECREATIONAL TRAVEL 5

POLICY BARRIERS AND INVESTMENT DECISIONS IN INDUSTRY

13

TRADEOFES OF MUNICIPAL SOLID WASTE PROCESSING ALTERNATIVES

17

END-USE ENERGY CONSERVATION DATA BASE AND SCENARIOS

23 


\title{
ENERGY EFFICIENT BUILDINGS
}

\section{The Causes of Litigation Against} Energy Efficient Building Codes

\begin{abstract}
Unlike traditional building codes, which have been imposed to regularize construction practices, some new energy efficient codes attempt to mandate change. These new codes require as much conservation as is cost effective for the home occupant. Compared with traditional codes, such new codes are usualiy more rigorous, increase costs, and are more disruptive to the building industry. This paper discusses three industry suits against building codes. Two suits claimed that supposedly cost-effective codes were too rigorous (the California Residential Building Code and the Farmers Home Administration standards). The third suit claimed that the code (the California nonresidential code) was overly prescriptive. The specific objections made in the Iitigation against these three codes are listed and the industry conditions and beliefs behind the objections stated in court are discussed. other cases attempting to strengthen building codes, such as Polrized Corporatin's current suit against ASHRAE $90-75$, are not examined in this paper.
\end{abstract}

Three objections against rigorous codes are based on anticipated higher costs of building under the new codes: 1) apprasials would not be raised enough to compensate for higher construction costs, especialiy in the FmHA program; 2) low-income buyers would be priced out of the market, and 3) capital shortages in the loan market and higher costs would reduce availability of loans. Builders also claimed that the computed payback periods were too long. They felt that the additional costs of conservation measures should pay back to the first buyer, rather than paying back over the life of the biliding. They also argued that materials, such as glass fiber insulation, are unavailable, and that industries such as electric resistance heating will collapse.

One source of difficulty in adapting to new standards is the diffuse nature of the industry--there are many small independent builders who are not in close contact with professional associations. New information may not reach them, and adjustment to new requirments will be difficult. But for the same reasons, change would be very slow without building codes. Builders will experience hardships in the transition to new mandated practices, and may be inefficient until they have rethought old practices and adjusted to the new ones. For example, the proposed California code requires two inch by $s$ ix inch framing in many parts of the state to accommodate R-19 insulation. While builders could minimize cost increases by changing from two-by-four studs on 16 inch centers to two-by-six on 24 inch centers, they 
may instead minimize changes in layouts by instaling twoby-sixes on 16 inch centers. Such fallures to optimize quickly will increase costs considerably in the transition period.

Two general beliefs not stated in court are behind many of the explicit court allegations. The first unstated belief is that the market, not the government, should determine what is built. The second is that the buying public does not want more efficient buildings.

Implementors of new building codes can increase their acceptability by: 1) working with lending institutions prior to implementation, 2) making cost calculations understandable to the public, and 3 ) insuring that the codes are truiy performance-based. Occupants of efficlent buildings have lower utility bilis and thus more money available for mortgage payments or rent. Also, their bills undergo smaller seasonal fluctuations. If lenders had good information about these advantages, they might permit more favorable loan terms for such buildings. Next, if the cost calculations on which the codes are based are correct and widely understood by the public, special interests would be more reluctant to impede them. Finaliy, codes must be based on performance, allowing alternatives to prescriptions of materials and techniques. But many local building inspection departments are unable to evaluate innovative conservatin or solar techniques. Thus, to be true performance codes, code implementation must provide for staff and facilities to approve innovative plans without inordinate delay.

Two issues underlie many policy questions about energy conservation building codes. One is whether market forces will make the necessary adjustments without codes. Many factors suggest that they will not: 1) market decisions are based on currently low energy prices; 2) homebuyers are not always rational economic actors with respect to energy consumption (for example, prestige or comfort often supersede economic considerations; 3) builders overestimate the costs of change to be transitional costs, perpetuating current practices, and 4) given current energy prices and public awareness, the seller of a higher-priced efficient home is at a competitive disadvantage. The second underlying issue is whether or not governments should use building codes to accomplish long-range planning. Building codes which maximize cost effectiveness for the occupant depart from past codes and attempt to effect a change in building practices. The fallure of market forces, the longevity of housing stock and the large amount of energy involved argue for such mandated change. But if such mandated change is perceived as unfair, then many of the objections that have arisen in the past are likely to be made again. Initiators of such codes should be prepared for these objections. 


\title{
A Description of the Building Process
}

\author{
Explanation of the Flowchart: Diagram 2
}

The large flowchart included with part 5 of this report provides an overview of the building process and can be used to assess the impact of proposed policles. The chart is composed of two major elements: a base chart in blue line form and a transparent overlay chart. The base chart diagramatically portrays the current building process from inception through construction, occupation and eventual demolition. Included are the links, the actors, resources, policies, decisions, information and regulations of the process with an emphasis on how information about energy efflcient buildings is currently incorporated. The flowchart has blank spaces where other relevant factors, such as environmental concerns, could be added. As an aid to reading the flowchart, a simplified version is included at the end of this section.

THE BASE CHART is divided both horizontaliy and vertically. The vertical divisions represent the major sequential activities in the building process: a) programming, b) development planning/design, c) construction, d) completion/delivery, e) occupancy/maintenance, and $h$ ) destruction and replacement. The horizontal divisions both above and below represent the inputs flowing to these stages of the building process: Policies/regulations/standards, actors and motivations lead to the provision of either the resources (odd numbered) or the information (even numbered) necessary for the completion of any stage in the building process.

For the actors who provide the resources and information, the diagram presents the factors that both motivate and constrain their decisions. The diagram also indicates the relationship between primary and secondary actors. The diagram expands only some areas, emphasizing points where a change could encourage energy conservation. Once such a point is identified, the policy designer can trace the consequences of this change back through the actors providing the information or resource, the policies and standards affected. 
BUILDING PROCESS

DIAGRAM 2

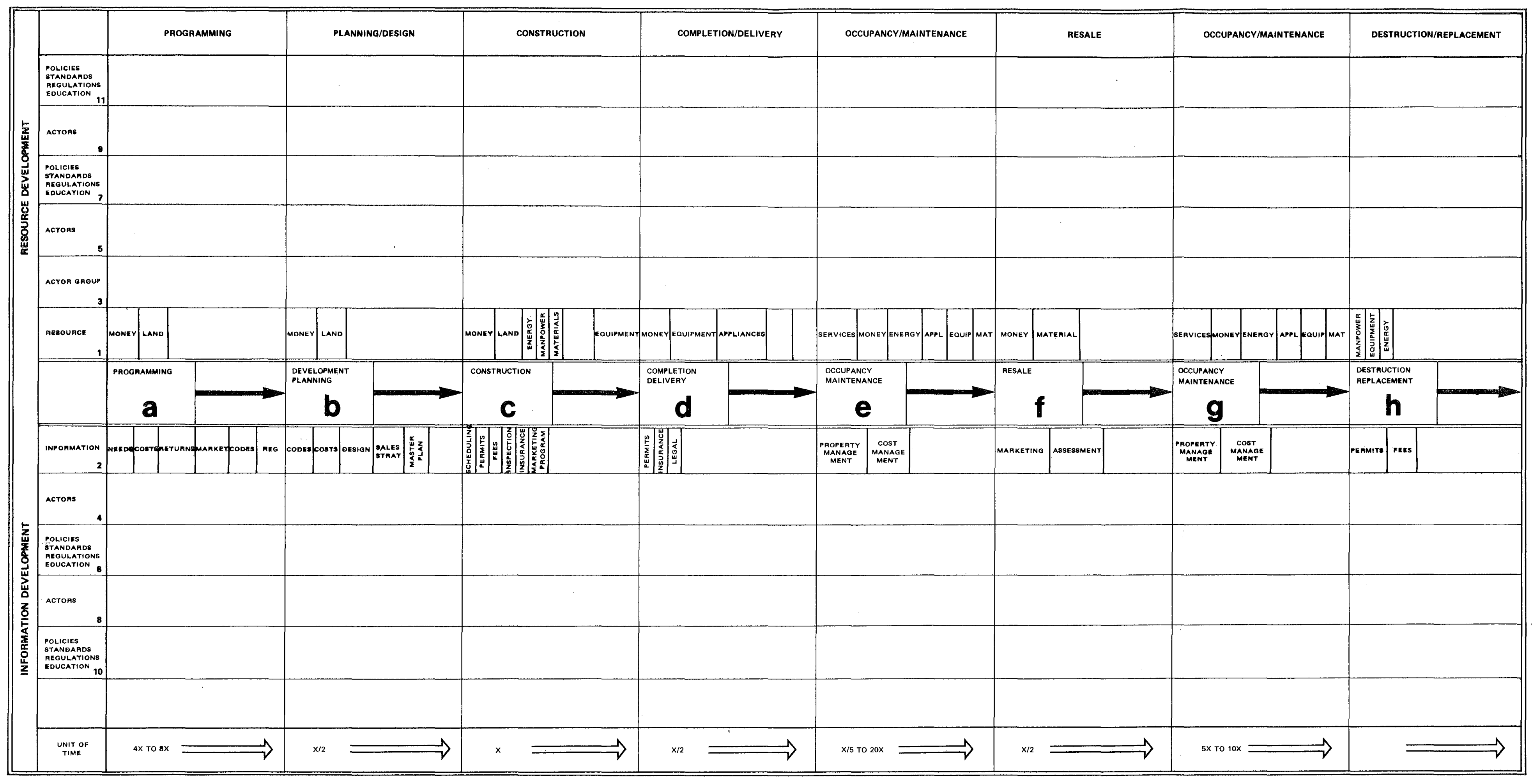




\section{ENERGY EFFICIENT RECREATIONAL TRAVEL}

Energy consumed for recreational travel is an important component of total transportation energy consumption. Most of this recreational travel takes place in the automobile, which not only consumes energy, but also poliutes, makes noise, and causes other environmental stress whlch thereby may diminish the recreational experience for the very travelers who use it. Accordingly, how to bring about a modal shift to a more efficient means of transportation for recreational trips is an appropriate policy issue. An examination of the traveler's decision-making process indicates that information is a weak link in the modal cholce decision. Moreover, the information is biased toward the private auto. In this report, we focus on an information policy designed to bring about a modal shift toward public transit for the weekend recreation trip.

We begin by summarizing the policy and placing it in the context of the issues it addresses. Following that, we develop in detail an information policy to link use of national parks with transit for the weekend trip. This policy derives from an examination of the importance of the recreational and weekend trips in terms of trip numbers, purposes, modes, and energy consumption. We then describe verbally and graphically the traveler's decision-making process. Several potential problems and policy targets are revealed, of which the information link is one. Finally, we present a broad spectrum of information policy suggestions that would strengthen this link.

The information policy we developed emphasizes the joint roles of the National. Park service (NPS) and the Department of Energy (DOE). Although the policy could be implemented by various agencies including DOE, the policy is couched primarily in terms of NPS's role because of recent legislation, described below, that authorizes them to address transportation and energy conservation issues. DOE's potential role is discussed after the structure of the policy is described.

In the past, the purpose of the NPS was to preserve natural resources rather than to bring people into park areas. The agency had neither the authority nor the funding to address problems of access to the parks. Very recently, however, Congress passed legislation (P.L.95-344) authorizing the NPS to formulate transportation plans and implement transportation programs. The purpose of the act is to support modes other than the automobiles for access to and within national parks and thus preserve the parks and conserve energy. Included in the legislation's mandate is the need to establish information programs to notify the public of alternative travel modes. 
In the spirit of the recent legislation, we suggest three components for the NPS to develop in its initial information dissemination program.

1. An inouiry and response system to centralize the multiple sources of recreational and transit information. This system could include the following features :

-a mail service, consisting of a pre-printed card with blanks for name, address, recreation area, travel constraints and requirements and special information.

-a telephone service, consisting of a toll-free telephone number, preferably an acronym such as FUNTRIP.

-a walk-in service at each park (e.g. a visitors' center), which emphasizes transit for on-site travel.

2. Brechures and pamphlets to convey information in an effective manner which should include:

-clear, specific and up-to-date transit facts, such as routes and schedules.

- the negative aspects of automobile travel, such as pollution and congestion.

- color photographs highlighting the recreational opportunities.

-detailed information about the site so recreationists do not feel compelled to maximize their flexibility by traveling in an auto.

3. Media campaigns to tap into the many and varied information conduits that exist today. Strategies should include:

-a nationally known and displayed logo, which the public would identify with a pleasant and reliable transit system.

-a speakers bureau to orient specific market segments to recreational transit.

-articles in newspapers and travel magazines.

-maps and displays in the telephone book, an information source widely used for trip planning.

-site condition reports, such as ski or surf bulletins, which mention transit opportunities.

DOE could strengthen this program in several ways. First, it could supplement NPS funding and analysis of park transportation. Data on energy consumption and energy conservation potential could be gathered and analyzed. Second, it could coordinate the information system; operation of the toll-free telephone number could build upon the experience of DOE's Solar Division with a toli-free public information number for solar energy. Third, it could develop public relations material on recreational travel. Fourth, it could initiate a demonstration project for recreational transit to determine energy savings. And finally, it can support research and development on energy-efficient public transportation systems. 
Section 2, divided into five parts, describes the background research that preceded the policy design. We note that decision-makers have often not recognized the importance of recreation as a policy issue. Problems related to recreation are often considered of secondary importance, to be dealt with only when more pressing concerns are resolved.

Part I contains the background data for recreational travel. Leisure-related activities have developed into an industry of economic importance. In 1972, expenditures for traveliing to and engaging in recreational activities approached $\$ 61$ billion, up from $\$ 50$ billion in 1970. For many people, travel is in itself a form of recreation. According to the 1972 National Travel Survey, persons from two out of three U.S. households took a trip during the year. Almost $54 \%$ of these trips were devoted to leisure and recreational activities. Between 1972 and 1974 , despite the Arab oil embargo, the number of trips for pleasure rose by over 37 million, a jump of $30 \%$.

On most recreational trips, the automobile was the preferred mode of travel, accounting for $81 \%$ of the total. Such dependence on the automobile has diverse and serious impacts: air pollution, traffic congestion, environmental stress, and consumption of land and money. Finaliy, leisure travel contributes to the consumption of gasoline. Data seem to indicate that recreational travel could account for between 15-30\% of all personal automobile use. This means that in 1975, personal passenger vehicles consumed between 11.5 and 22.9 billion gallons of gasoline in recreational travel.

Despite the importance of pleasure trips in terms of economic impact, individual iffestyles and expenditures, congestion and pollution in outdoor areas, and fuel consumption, there are virtually no policies developed specifically for recreational travel. Transit companies do not formulate policy for recreational travel, feeling that their first priority is to operate for commuters.

This material suggests that recreational travel is a target worthy of energy conservation policy. Public policy should be designed to lessen the American population's dependence on the automobile for leisure trips and consequently to conserve some additional transportation energy.

One of the strategies a successful policy can follow is to encourage actions which people might well take even in the abserice of any policy at all. During the fuel embargo, Americans did not cut down on the number of leisure trips they took. However, they did change the pattern of their recreational traveling by using buses and trains more. The overall rise in the use of these common carriers was achieved at the expense of the airplane as weil as the 
automobile.

It is not practical to assume that goverment policy will be able to affect all or even a majority of pleasure trips in the short run. However, some trips are likely to be more responsive to public policy. We have focussed our initial analysis on a specific trip type -- the weekend trip (Part II).

According to the 1977 National Travel Survey (Preliminary), almost 31 million households took weekend trips during the first three months of that year. Weekend travel represents about $40 \%$ of all trips over 100 miles taken in the United States; this percentage breakdown has remained approximately the same since 1972. If visits to friends and relatives are included, then fully $75 \%$ of all weekend trips are devoted to leisure and recreation. If we omit such visits, then recreational travel accounts for $26.5 \%$ of weekend trips.

For weekend travel, the modal split by percentage is:

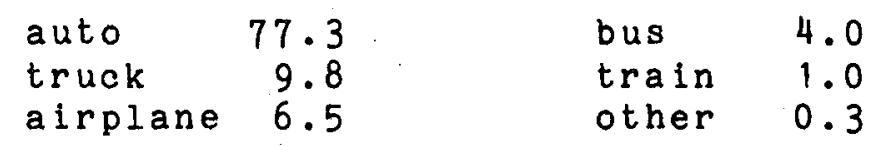

It is Iikely that the car is used more to give flexibility in timing and route choice that to extend the distance travelied.

Vehicle occupancy for weekend trips and recreational travel tends to be $33 \%$ greater, on the average, than for all other trip purposes. The highest occupancies occur at scenic areas of national reputation, catering to families. The occupancy rate generally increases as does the distance travelied. Lowest occupancy occurs at predominantly dayuse, water-oriented sites.

This may suggest that public policy focus on certain types of trips to encourage transit use: for example, the shorter weekend trip or trips to water-oriented sites. On longer trips, with their higher vehicle occupancies, the car is an energy-efficient form of transportation.

Although the auto is still the overwhelming favorite for weekend trips, its use as a percentage of total travel has been declining slightly slnce 1972, from $88.9 \%$ to $87.1 \%$. The use of bus and train increased a bit, although the two modes together only account for $5 \%$ of all weekend trips. The mode predominates, because the automobile serves functions other than transportation. Most people do not travel to penetrate the countryside; they want to remain close to the safety, comfort, and shelter of their cars. 
In Part III, we have developed a flowohart to depict the recreational experience. This experience is represented as a system--a. set of components and thelr interrelationships. Decision-makers can use the flow chart to aid in determining which components of the system could be altered to achieve a greater balance between the automobile and other modes for recreational travel.

Previous studies on recreational travel have neglected the potential for transit use. They have also overlooked the preferences and motivations of the users of the transportation system. Our description of the recreational experience focuses on the way the user decides to adopt a mode of travel.

The system depicted in the flowchart divides the recreational experience into five phases. During the PLANNING phase, the recreationist makes most of the major decisions of the trip: where and when to go, what mode to use, who will go, what to do, etc. During the TRAVEL TO phase, travel time is often an important variable in the selection of mode and route. However, travel time can become a less critial variable if the trip itself is enjoyable. ON SITE experiences are the portion of the trip most often associated with "recreation". TRAVEL FROM, the fourth major phase, resembles the "travel to" phase in terms of origin and destination; however, the route and time spent in transit may vary considerabley. RECOLLECTION, the final phase, generaliy forms the basis for planning and making decisions for the next recreational experience.

Each phase incorporates a number of decisions which must be resolved before the next phase can be entered. There are three major factors influencing each decision: information, criteria, and constraints.

The recreational system depicted in the flow chart should be understood in the context of the environment in which it has and is still developing. The environment includes factors that are relevent to the recreational experience, but which policy-makers may not be able to affect very much in the short run. These factors include: social trends, location of existing recreational areas, physical infrastructure, government policies and regulations, and natural factors.

In Part IV, we use the flowchart to identify which aspects of the recreational system need to be addressed to alter the modal distribution, increase the use of public conveyances, and conserve energy in recreational travel. Our analysis reveals that the modal decision occurs after two other decisions, "Where to Go" and "When to Go". These first two decisions may determine the modal choice for the recreational trip and possibly eliminate transit as an 
between transit and recreational entreprenuers, such as restaurants and hotels.

B. Desian a centralized system of recreation/transit infermation. This could include

-a central and well-known address to which people could write.

-a regionally or nationally known toll-free telephone number.

c. Stress the recreational petential of transit trips when develeding information systems, through such techniques as

-market segmentation.

-media campaigns which emphasize enjoyment. 


\section{POLICY BARRIERS AND INVESTMENT DECISIONS IN INDUSTRY}

The industrial sector provides policy-makers with substantial opportunity for effecting energy conservation. Each year decisions are made regarding investments in conservation measures that could substantially reduce energy consumption. Many of these decision outcomes could be influenced by applying the appropriate government action-financial incentives, regulatory restrictions, and/or information provision. Government intervention should be confined, however, to situations where it is both necessary and likely to be effective. To this end we have developed a methodology to aid policy-makers in the recognition of such situations and facilitate understanding of the barriers that block conservation efforts.

The methodology employs two flow charts and a matrix. The flow-charts detail the principal participants, information flows, and criteria and constraints which underlie the investment decisionmaking process. The matrix expands upon the set of criterla and constraints given in the flowcharts and analyzes how characteristics of the particular sector and attributes of the measure in question interact to form barriers to conservation efforts.

Industrial decision-makers consider a number of factors before deciding. whether or not to invest in a conservation measure. Each factor or attribute can increase the likelihood of a measure's adoption or pose a barrier to it. We have identified seven primary attributes:

1. Cost Effectiveness

2. Relative Cost

3. Unreliability (the expected unscheduled downtime)

4. Disruption to Install

5. Technical Sophistication Needed to install the measure

6. Environmental Impact

7. Change in Dependency of the firm on outside fuel supplies.

During a preliminary examination, it may appear that a particular attribute increases the desirability of a given conservation measure. For a particular industrial subsector, there may exist, however, other factors--economic, regulatory, or technical --which can alter the attribute's impact on the investment decision. We refer to these other factors as subsector characteristics and have identified nine:

1. Market Growth

2. Capital Intensity

3. Energy Intensity

4. Access to Credit

5. Rate of Return on Investment 
6. Regulatory Restrictions

7. Age of Plant

8. Avallability of Fuels

9. Technical Complexity

We have, therefore, broken down the investment decision into a three stage analysis to include considerations of the effects and interactions of attributes and characteristics. First, decision-makers consider the influences of the conservation measure attributes on the desirability of implementing the measure. Second, they estimate the impacts of the industrial subsector characteristios on each attribute. Finally, they re-evaluate the influences of attributes in light of the impact of characteristics.

To incorporate this three stage analysis into our methodology, we developed a matrix which arrays columns of attributes againest rows of characteristics for the selected conservation measure. First, each attributes is qualitatively rated high, medium, low or ",$+ "$ "0," "-." A low or "+" rating indicates that the attribute increases the likelihood of the investment. Any other rating denotes a potential barrier to implementation. Second, the effects of each characteristic on the evaluation of each attribute is determined and either a "+," " $0, "$ or "-" is entered in every cell of the matrix (i.e. the interface of an attribute and a characteristic). A " " rating means the interaction favors the adoption of the measure; a "-" rating denotes a potential barrier. Finally, attribute columns can be examined for "-" ratings which might alter the favorable impact of an attribute on the investment decision. By inspecting the matrix, one can determine:

1. Which conservation measures have no apparent barriers in a given subsector and therefore require no government action.

2. Which conservation measures have so many apparent barriers in a given subsector that only massive government intervention appears as a solution for achieving implementation.

3. Which conservation measures are reasonable targets for government policy after further investigation of the barriers revealed by the methodology.

Policy-makers may then refer to the flow charts to ascertain which participants in the decision-making process are most likely to be concerned with the particular barriers which have been identified. By knowing the nature of barriers and the identity of participants concerned with them, policy-makers can more easily select the most effective policy to influence the outcome of the investment decision. The final choice of an effective policy is not uniquely determined by this analysis; rather, the set of choices is reduced. 
To test the methodology, we selected four conservation measures--Improved Housekeeping, New Plant Construction, Waste Heat Recovery, and Process Change/Major Renovation-and three industrial subsectors in California--steel, chem 1cals, and petroleum. The conservation measure attributes describing Improved Housekeeping and New Plant Construction were arrayed against subsector characteristics for the steel and chemical subsectors; attributes associated with Waste Heat Recovery and Process change were arrayed against the chemical sector characteristics.

We found none of the conservation measures to be completely free of potential barriers requiring government action. Improved Housekeeping (improvements in operating and maintenance procedures in existing plants) however, has only one attribute--Cost Effectiveness--which under prevailing conditions today, fails to increase the likelihood of the measure's adoption in either the steel or chemical subsector.

We found no measure to have so many barriers that only massive government intervention could achieve implementation; they are all likely targets. Potential barriers indicating the need for more quantitative work to decide if governmental action should be taken are identified in individual matrix cells (i.e. in the attribute/characteristic interfaces).

Matrices arraying conservation measure attributes against subsector characteristics of the California steel subsector were completed by staff who relied upon data found in the Iiterature and conversations with industry spokesmen. Similar matrices for the chemical subsector were completed by Mr. Richard W. Barnes, relying upon his thirty years of experience in the chemical and petroleum subsectors plus extensive consultations with industry contacts. The reasoning used by Mr. Barnes to complete the arrays and that used by our staff were found to be quite similar. This suggests that policy-makers also will be able to duplicate the thinking process engaged in by industrial decision-makers and be successful in identifying potential barriers to conservation measures.

The second section of the report traces, with the aid of flow charts, the process of investment decisions. The organizational structure is generalized and may vary considerably, but the functions indicated must be performed regardiess of firm size, degree of sophistication, or kind of conservation measure. The flow charts and text portray large corporations as the model for industrial organization because such firms account for the bulk of industrial energy use; an abbreviated discussion is provided for small firms. The decision areas important for the installation of conservation measures differ if the equipment is to be retrofitted 
or included in the design of new facilities; consequently, two flow charts were formulated. The text in section 2 provides guides for the charts.

At The far left side of each chart are listed categories of major factors in the declsion process; information, actors, criteria \& constraints, and motivations. The horizontal headings of each chart--Concept Introduction (or Conceptualization and Design), Analysis and Decision, and Implementation--represent the three broad stages of the decision process. The specific factors which are important at each stage--who the actors are, which particular criteria \& constraints they apply, what their motivations are, and what kind of information they receive--change as the decision process advances. The pertinent factors can be located by examining the interfaces of factor categorles and decision stages. In addition, the charts reveal the points in the decision-making process at which policles can be applied; given a particular obstacle to conservation, the charts suggest the most likely points and the general types of policy to achieve successful implementation. 
TRADEOFFS OF MUNICIPAL SOLID WASTE PROCESSING ALTERNATIVES

\section{A. OBJECTIVE AND ISSUES}

Garbage generation in the United States is expected to increase from the 1975 level of 3.4 pounds per person per day to five pounds per person per day in 1990 (U.S. Environmental Protection Agency 1977:20). Many stategies have been proposed to cope with the anticipated increase. The objective of this report is to assess the performance and advantages of several garbage processing or disposal (landeill) techniques, and to examine the issue of large scale recycling of waste material.

Five general methods of garbage disposal and processing are discussed: close-in landfili, remote landfill, refuse derived solid fuel (RDSF), pyrolysis and incineration. Landfiling is one of the most prevalent garbage disposal techniques in use. The method is inexpensive, requires small capital outlays, and is relatively energy efficient. But close-in landfill sites are nearing capacity and additional close-in sites are either unavailable or extremely expensive.

Landfills can also be an environmental hazard (e.g. water contamination, odor, occupation of land, production of explosive methane gas). Moreover, landfilling amounts to disposing of potentially energy-rich materials and recyclabl resources. Remote landfill is costly, since operating costs for landfill increase dramatically with distance from the area served. Increasing attention, therefore, has been given to the possibllities offered by the recycling of source-seperated materials.

The importance of such issues is exemplified by the number of states implementing waste disposal policies. For example, California has implemented over 130 recycling programs in different communities, while six major cities which together comprise the bulk of the state's population are considering the creation of large-scale resource recovery facilities.

The major issue at this time concerning municipal solid waste disposal is whether to continue with landfill as the primary method or to use some combination of source separation, resource recovery and energy generation with landfill. The constraints surrounding this issue are capital and labor costs, technical feasibility, environmental impacts -- especially air pollution - marketability of the derlved energy and recycled resources, and public cooperation. 


\section{B. DESCRIPTION OF THE RESOURCE RECOVERY PROCESS}

The recovery of energy from MSW through source separation programs and resource recovery facilities occurs at the back end of a long process -- after virgin materials are transformed into consumable products, distributed, used and ultimately disposed as solid waste. The large diagram which accompanies Part 2 of this report presents an overview of this process and emphasizes other points in the resource stream where energy recovery from materials reclamation can occur. On the following page, a smaller summary diagram provides an outline of the more detalled larger diagram.

Structuraliy, the diagrams consist of the following components: $i$. The main activities and associated actors and resources; 2. Existing government policies related to these activities; 3 . The motivational concerns of the main actors.

\section{The Main Activities, Resources and Actors}

These comprise the underlying skeleton of the whole schematic. The six main activities are depicted from left to right across the lower portions of the charts. They include Mining and Harvesting, Manufacturing, Converting, Distributing, Consuming and Disposing. Resources, directly above the main activity in the more detailed diagram, are processed at each of these six stages and change their identities as they move from left to right. For example iron ore, which is at the first mining activity, becomes transformed into steel sheet, then steel cans, food containers and finally a component of consumer garbage.

The resource flow is signified by solid lines which connect with the associated actors at each stage of the process. From different points along these resource paths, scrap materials can be removed and recycled into the main resource flow. In this way, we see a returnable bottle entering a recycling loop through the food store and then re-entering the main path through the beverage maker. The recycling paths are represented by non-solid lines that connect the recycling actors in the upper half of the diagrams with the main activities below.

\section{Existing Policies}

Present government policies influence both the resource and recycling activities at each stage. The former sets of policies are found in the lower portion of the diagrams and are connected directly to the main activities; the latter are found in the top portion of the diagrams and are connected directly to the recycling actors which they affect. 


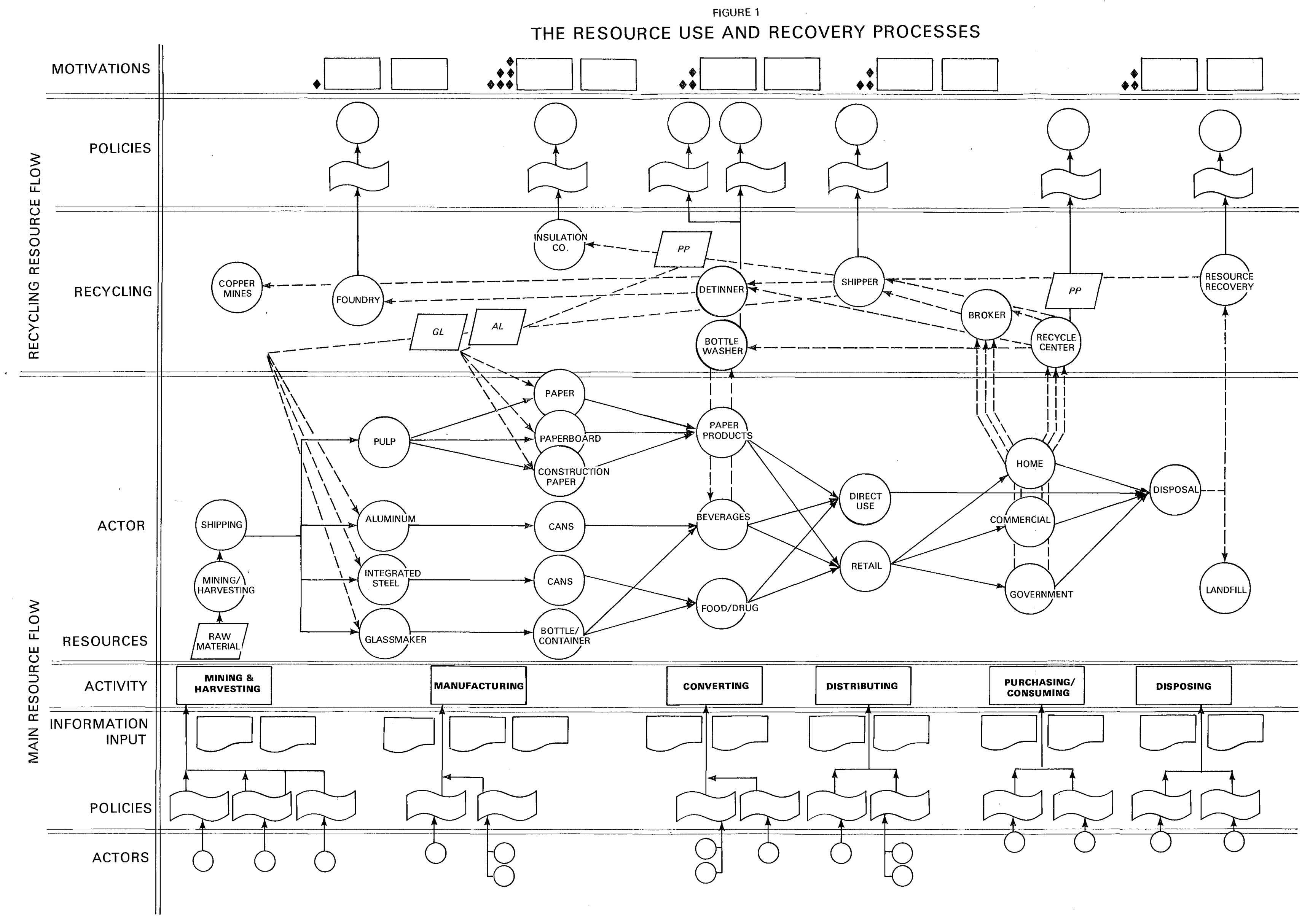




\section{Motivational Considerations}

These are social and economic forces that motivate the main actors along the main resource and recycling paths. For the main resource use actors, these are found directly below the central activity; for the recycling actors, they are shown at the top of the diagrams alongside single or multiple diamonds. The diamonds refer to key decision points where the actors have the cholce between recycling material or discarding it, and between using recycled material or virgin material.

\section{CONCLUSIONS}

It is not possible to determine which of the three techniques--RDSF, pyrolysis and incineration--is more economically advantageous. Only site specific analysis can determine the best choice of techniques because three variables--design options, financing arrangements and marketing arrangements--differ too significantly from site to site to allow generalization of their effects on the choice of process.

Recycling of glass, aluminum and ferrous metals is compatible with energy generation whether done mechanically at the recovery plant or by the public prior to municipal solid waste (MSW) delivery. This holds because these materials must be removed prior to energy production. Of these recyclables, ferrous metals are most efficiently recovered through mechanical means. At present, glass and aluminum appear to be best recovered through public recycling and source separation programs, although this situation is subject to state-of-the-art developments in recovery equipment, local market conditions and the costs of local collection. Newsprint can be either recycled or converted to energy, but the former appears more energy efficient.

An effective source separation program, in a high participation scenario, can reduce the MSW by $15 \%$. It is important to consider this potential in planning resource recovery options since any reduction in the MSW stream will have a bearing on the size of the facility that will be necessary.

The location of waste processing facilities is the most important factor in assessing the pros and cons of any particular process. MSW processing plants are of obvious interest in densely populated areas where pollution problems and in particular air pollution are most dramatic. Preference for one process rather than another does not necessarlly reflect data derived from market forces alone. California, for example, has imposed stringent regulations 
on air pollution - hence preference in this state is given to pyrolysis despite economic disadvantages (both capital and operating costs), since air pollution is negligible when it is used. Also under consideration in California are low-cost, package incinerators but these, too, are contingent upon federal and state evaluation of their air quality impact.

The separate collection of recyclable materals is generally compatible with garbage reprocessing centers. The degree of compatibility, however, is dependent on several factors, including the types of materials collected by each system, the market value of the recycled products, the cost of collection and the efficiency of the mechanical recovery equipment.

Newsprint recycling is the activity potentially most in conflict with operation of a resource recovery plant since removal of newsprint from the waste stream will affect the heat value of the fuel and the subsequent revenue derived. The loss of heat value is slight--around 10\%--and is more than compensated by the higher energy savings achieved by recycling the fiber, rather than burning it. These savings are around $12 \%$ per collected ton of newsprint compared to the use of RDSF converted to steam, and almost $300 \%$ compared to RDSF converted to electricity..

of all the materials, newsprint is the most suitable for separate collection. It has a relatively long history of profitable and successful collection both in separate vehicles and in conventional garbage trucks which have been modified. Less cost effective have been source separation programs which collect, besides newsprint, glass and metals. In some communities, high labor and other collection-related costs may seriously deter the creation of such multimaterial programs.

In other cases, however, multi-material collection can offer a favored alternative to the use of costly materials recovery equipment in a garbage processing plant. The exception to this generalization is ferrous metals recovery where magnetic separation has a far superior recovery efficiency than separate collection. It averages $94 \%$ recovery of this metal. Source separation programs, by comparison, can reclaim $15 \%$ in a high participation scenario. However, steel cans collected separately have a much higher degree of purity than mechanicaliy separated ferrous metal and can therefore command a higher market price, which may be an offsetting consideration in some areas. In any event mechanical recovery of ferrous metal will be cost effective even with prior removal of some of the metal by a source separation program. 
The inclusion of aluminum recovery equipment at a resource recovery facility appears to be uneconomical at this time. The equipment has not been throughiy demonstrated. It is costly - $\$ 500,000$ or more for a 1000 tpd plant -- which requires that a large volume of aluminum be recovered. At present, its not certain that sufficient aluminum is avaliable. Regardless of whether aluminum is recycled via on-site plok-up or through recycling centers, between 25-40\% of the valuable metal is likely to be collected by the pubilic. The remaining tonnage is further reduced by inefficiencies in the mechanical recovery process. Uncertainty also results from the possibility that a beverage deposit law could significantly reduce the volume of aluminum in the waste stream.

Mechanical separation equipment can recover about $50 \%$ of the glass available. This is about the same level of recovery that can be expected from source collection, in a high participation scenario. of the two systems, source collection provides many advantages. It relies on proven technology as opposed to the equipment in mechanical systems and it recovers a higher grade of glass whlch can be colorsorted and readily marketed. Because of its low market value, glass is not a revenue-maker for either recovery system and so low annual costs are an important consideration. In this respect, glass recovery via source separation has the advantage of "piggy-backing" onto the collection of other more valuable materlals at little extra expense. 


\title{
END USE ENERGY CONSERVATION DATA BASE AND SCENARIOS
}

\begin{abstract}
The end use energy conservation scenarios discussed below show the combined effect on energy consumption of implementing a number of conservation measures. The scenarios serve two overall purposes. First, they provide a contrast of a series of nonconservation cases based on assumptions of growth rate and appliance saturation with conservation cases based on similar assumptions. Second, they provide detailed data and documentation for the savings potential for each conservation measure, the stock affected, and the calculation of total energy savings. Included are conservation measures of both a behavioral nature (e.g. night thrermostat setback) and a technological nature (e.g. better hot water heater insulation). Several water conservation measures and the associated energy savings were also incorporated to demonstrate how water conservation could be factored into a comprehensive energy conservation program.
\end{abstract}

The scenarios include assumptions about economic, demographic, behavioral and technological variables, such as population, growth and decay of energy using stocks, appliance saturation, and conservation implementation levels. Some assumptions are imbedded in projections used as input to the scenarios; these assumptions cannot be changed directly and are so noted in the main report. Other assumptions form the basis of calculations made and can be changed to construct alternative scenarios; these also are indicated. Some of the major assumptions are: 2.1 births per female between 1970 and 2020; a more than doubling of residential units; a decline in persons per residential dwelling from 3.03 in 1970 to 2.56 in 2020 ; annual growth in real per capita income ranging from 1.76 percent to 2.5 percent; an increase in commercial floor space per capita from 126 square feet to 209; a growth of frelght proportional to industrial growth; an increase in the time spent in automobiles from 55.8 minutes per person per day in 1970 to 80 minutes in 2020; a four fold increase in energy prices for the industrial sector; and a 3.34 percent average annual per capita growth rate (a continuation of the historical trend) in the value of industry shipments.

Quantitative estimates of energy consumption and conservation potential in the major residential and commercial end-uses, transportation modes, and industrial subsectors have been made. The residential and commercial savings include the anticipated effect on energy consumption of the new California residential and non-residential building codes and efficiency standards; estimates of the savings potential were taken directly from the California Energy Commission's public testimony and forecasts. The savings estimates are based upon the individual conservation measures that comprise the codes. These measures could be 
implemented in other regions through alternative mechanisms to codes and standards. The estimates of the savings potential attributable to the code are, therefore, tantamount to the savings estimates expected from implementation of the combination of measures that the codes embody, given climatic zones similar to the five factored into the estimates. In most cases, the maximum potential savings from a given measure can be estimated for any region of the nation by making the appropriate adjustment to account for changes in the scale of factors such as population and energy using stocks. In some cases for the residential and commercial sectors, the savings potential also must be adjusted to account for climatic conditions or other factors unique to the region.

For each measure and for the total scenario, a base case and a conservation case were computed. The cases differ by the exclusion or inclusion of the effects of the conservation measure(s). The end use saturation changes over time. The same progression of saturation changes are maintained between the base case and the conservation case to isolate the effect of the conservation measure(s) applied. Similarly, population projections and growth and decay rates of energy using stocks were maintained between the base and conservation cases.

Most of the scenario assumptions which were made can be changed to reflect different conditions, such as attitudes regarding family size, durability estimates of energy using stocks, or lifestyle changes that affect the purchase or use of a given appliance or transportation, mode. The implementation level of a conservation measure also can be changed to reflect a variety of responses to a given policy. In addition, conservation measures can be combined and new ones added.

For the residential, commercial and transportation sectors, the conservation measures are chosen from matrices that pair a wide variety of conservation measures with the corresponding end uses. The selection of measures can be varied and measures can be isolated to reflect either the policies or end uses that are of particular interest. Many combinations are possible but care must be exercised to avoid double counting. Scenarios were constructed that include conservation measures excluded from the scenarios which are reported below. The measures were excluded to avoid the double counting problem. Due to time and budget constraints, not all the scenarios that were constructed are described below, and only a subset of all possible conservation measures have been quantified and included in the scenarios that are discussed.

The residential and commercial end uses, transportation modes, and industrial subsectors for which the scenarios are 
constructed are listed below.

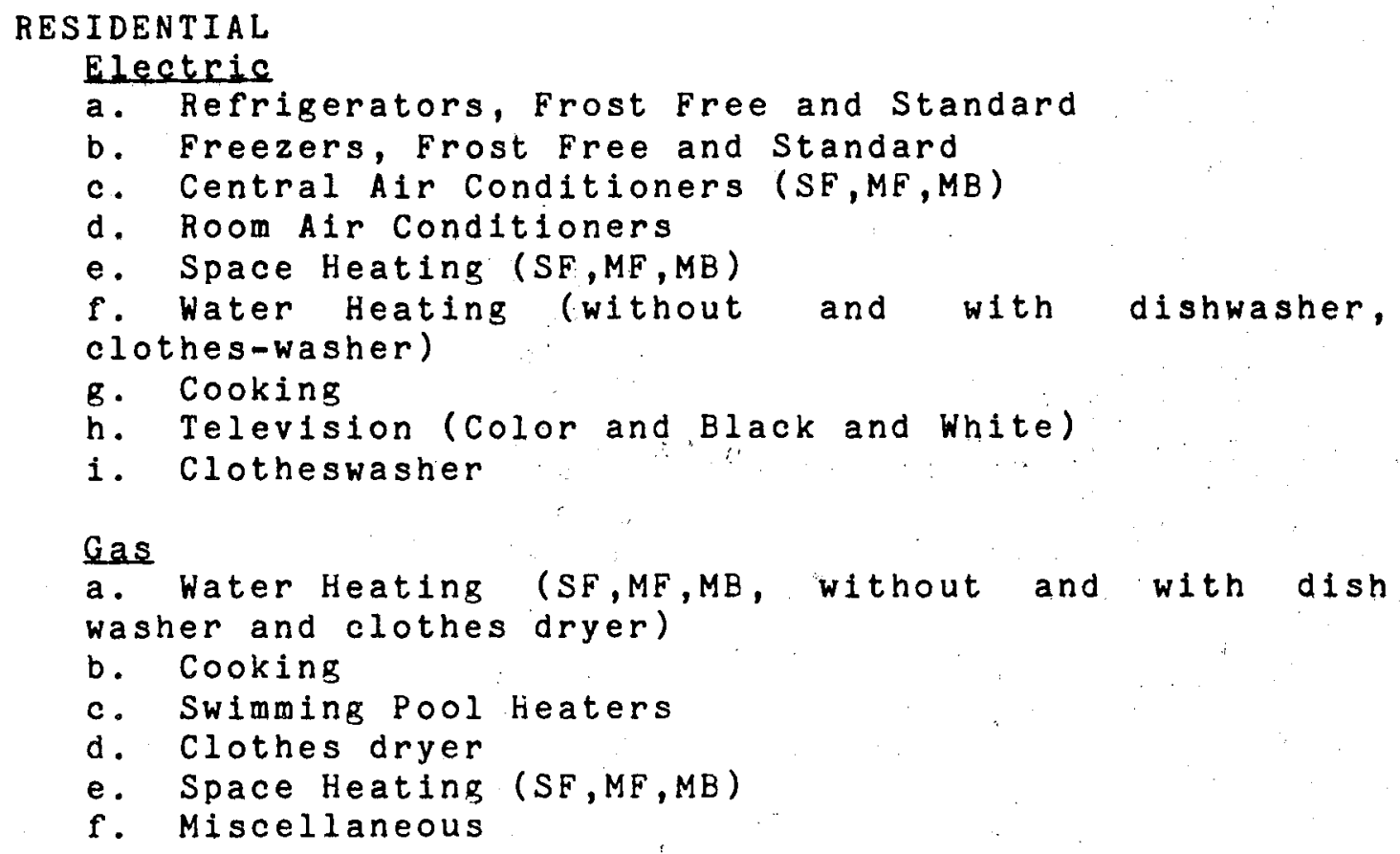

COMMERCIAL

END USES
a. Heating
b. Cooling
c. Waterheating
d. Lighting
e. Other

BUILDING TYPES

a. Retail-Wholesale

b. Office

c. Auto-repair

d. Education Services

e. Health Services. 80

f. Hotel-Motel

g. Miscellaneous all others 75,554

82

70
SIC CODE (40-99, excluding 88 and 491) including 50-59, excluding 554 $60-67,72-73,86$

\section{TRANSPORTATION}

Passenger

a. Automobile

b. Light Truck and Van

c. Airplane (commercial)

d. Bus (intercity, school, and local)

e. Railroad

f. Motorcycles

g. Other (mass transit, private aviation, recreation, 
etc. not included above)

\section{Ereisht}
a. Truck
b. Railroad
c. Airplane

INDUSTRIAL SUBSECTOR

$\begin{array}{lr}\text { a. Agriculture } & 01,02,09 \\ \text { b. Cement } & 324 \\ \text { c. Chemicals } & 28 \\ \text { d. Construction } & -- \\ \text { e. Food and Kindred Products } & 20 \\ \text { f. Glass } & 322 \\ \text { g. Iron and Steel } & 331 \\ \text { h. Petroleum Refining } & 29 \\ \text { i. Kubber } & 30 \\ \text { j. Stone, Clay and Glass } & 32 \\ \text { k. Primary Metals } & 33 \\ \text { l. Fabricated Metals } & 34 \\ \text { m. Machinery } & 35 \\ \text { n. Electronic Equiptment } & 36 \\ \text { o. Transportation Equiptment } & 37 \\ \text { p. Lumber } & 24 \\ \text { q. Paper } & 26\end{array}$

In the residential and commercial sectors, a building block approach was used to facilitate the scenario calculation and to increase flexibility of the calculation tool. The building block is a data sheet on which is contained specifi: information about each conservation measure and the stock it affects.

In the transportation and industrial sectors, this degree of data flexibility was not possible due to data limitations. In the transportation sector the data were collected from a number of published sources. In the industrial sector, our estimates are based on an unpublished report for the National Academy of sciences. In this study, data were collected nationally for ten major industries by polling experts on the conservation potentials of their respective industries. These potentlals were revised by California industry experts to determine the extent to which the national data apply to California. Energy conservation projections for U.S. Industry under conditions of an assumed four-fold increase in fuel prices have been modified to apply to California.

Computer software was developed to construct scenarios that calculate the cumulative effect of various conservation measures. The basic approach for the conservation scenario construction is to quantify base year (residential-1975, 
commercial-1970, transportation and industry-1974) unit energy consumption by end use, travel mode or industrial subsector, reduce unit consumption by the estimated conservation potential in the appropriate year, adjust for saturation, and extrapolate by implementation levels and projections of housing units, commercial floor space, travel demand or industrial growth that account for growth and decay of the appropriate energy using stock. The projections were made for 1980, 1985, 1990, 1995, 2000 and 2020.

Future energy consumption for many erd uses (e.g. cooking, television, buses and motorcycles) was projected without the effect of any conservation measures. The coverage of end uses, transportation modes, and subsectors for which energy consumption has been estimated, however, is almost completely comprehensive. Consequentiy, projections of total energy consumption may be overstated and projections of energy savings from conservation may be understated. This understatement of potential savings is offset, somewhat, by the assumption of a $100 \%$ implementation level, which is probably higher than what will actually occur, especially in the short run.

The behavioral and technological measures that are incorporated in the scenarios were selected on the basis of their potential for effecting large energy savings in the major end uses within each sector. The measures included in the scenario are as follows:

Industrial sector--housekeeping (leakplugging, equipment maintenance, insultaion); process improvements; waste heat recovery; new, more efficient facilities; in-plant recycling.

Commercial Sectorobuilding and appliance efficiency standards for water heaters, spaceheaters, and air conditioners in new and old buildings; low-flow devices to reduce water consumption and solar water heaters with efficient backups; and reduced and task lighting in new buildings and delamping in old buildings.

Residential Sector--solar water heating systems with efficent electrical backup heaters designed for loads reduced by. water conservation; building and appliance efficiency standards for space heating and air conditioning, and replacement of frost-free refrigerators and freezers by non-frost-free units.

Transportation Sector--reduced travel speed, smaller and lighter weight automobiles with improved engines; continuously variable transmissions and streamlining of trucks with emphasis on diesel engines; airplanes with high by-pass engines on narrow bodies and improved passenger load factors; and streamlined, lighter 
passenger and freight trains with improved passenger load factors and reduced empty freight car back hauling.

The impacts of these conservation measures are illustrated in Figures 1-4, which present consumption by sector. The figures show similar results--a more gradual growth of energy consumption in the conservation case compared to the base case, resulting in a widening gap between the two cases over time in the total amount of energy consumed. By extrapolating the growth variables, a gap results between the two cases by the year 2020 of approximately 6.3 quads, which is $115 \%$ of 1975 energy consumption. Total energy consumption increases from 5.5 quads in 1975 to a 2020 estimate of 13.2 quads with conservation and 19.5 quads without conservation. The largest savings occur in the industrial and transportation sectors- -2.7 and 2.4 quads respectively--and the smallest savings in the commercial sector--0.6 quads--and the residential sector--0.7 quads; the sectors with the largest savings are the ones with largest consumption.

No analysis of the growth rates of the variables that partially determine the magnitude of energy consumption in each sector (e.g. per capita value of industrial shipments, travel demand, rate of increase in commercial floor space or number of residential housing units) has been made to determine the most liekly rates. Varying the growth rate for one such variable will change the amount of energy consumption and savings. A change in the rate of growth could be attributable, for example, to a change in population, fuel availability or attitudes and values; these in turn may result in changing preferences for type or density of housing, demand for goods and services, and derived demand for intermediate and primary industrial production.

A more detailed inspection of each sector reveals the end uses and conservation measures from which savings are realized (Figures 5-8). The shaded portions of Figures 7 and 8 indicate consumption with energy conservation; the unshaded portions represent consumption without conservation.

In general, the largest end uses have the largest savings. The modes, enduses or subsectors having the greatest absolute savings are not always the ones with the highest savings potential (expressed as the ratio of unit energy savings to unit energy consumption). For example, in residential and commercial air conditioning, large percentage savings can be realized from improved building and appliance efficiency codes and passive solar housing. In the industrial sector, the food, construction, and iron and steel subsectors have higher savings potential than the petroleum refining and chemicals subsectors, which have the 


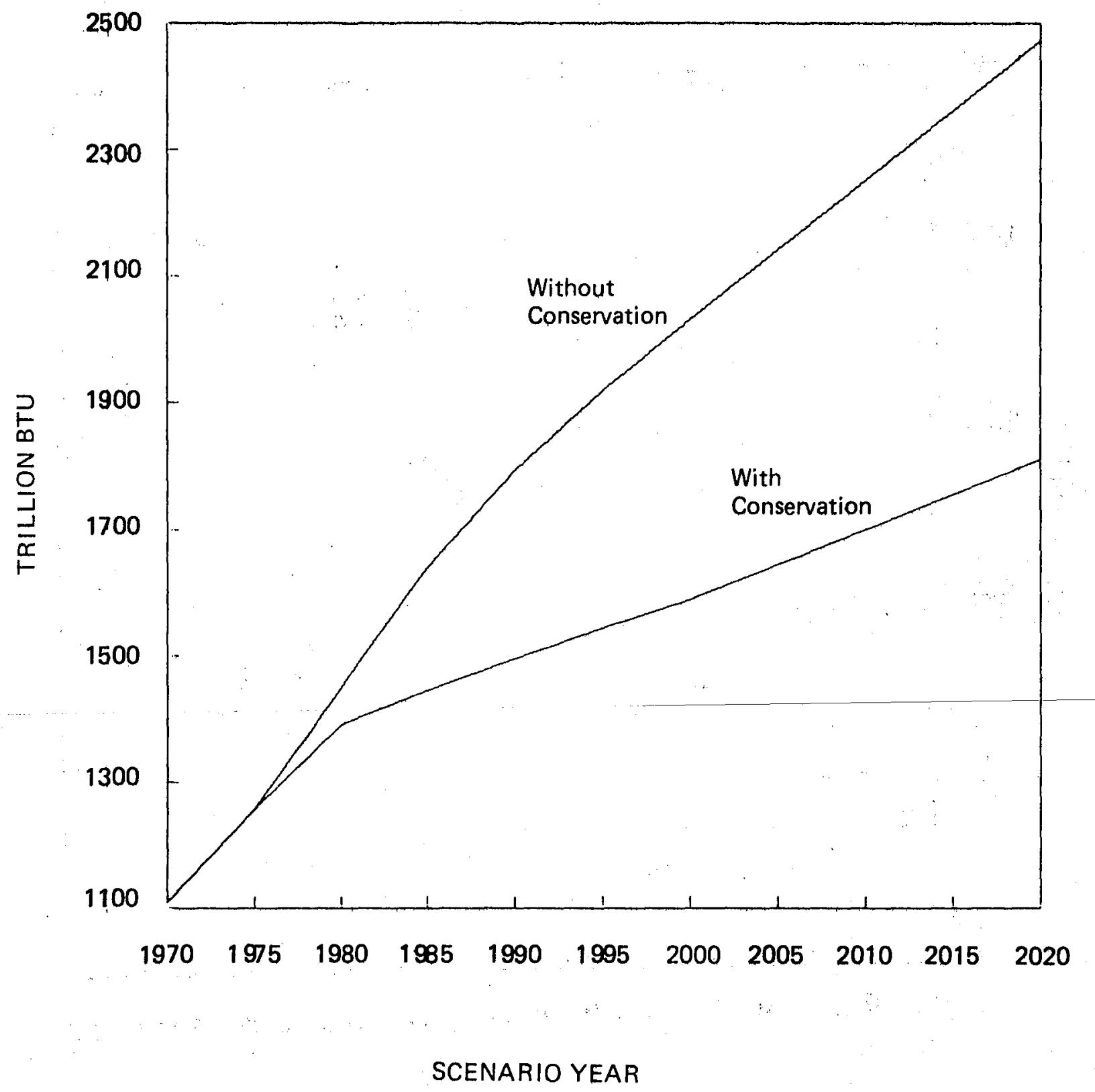

Figure 1. Residential Sector Energy Consumption. 


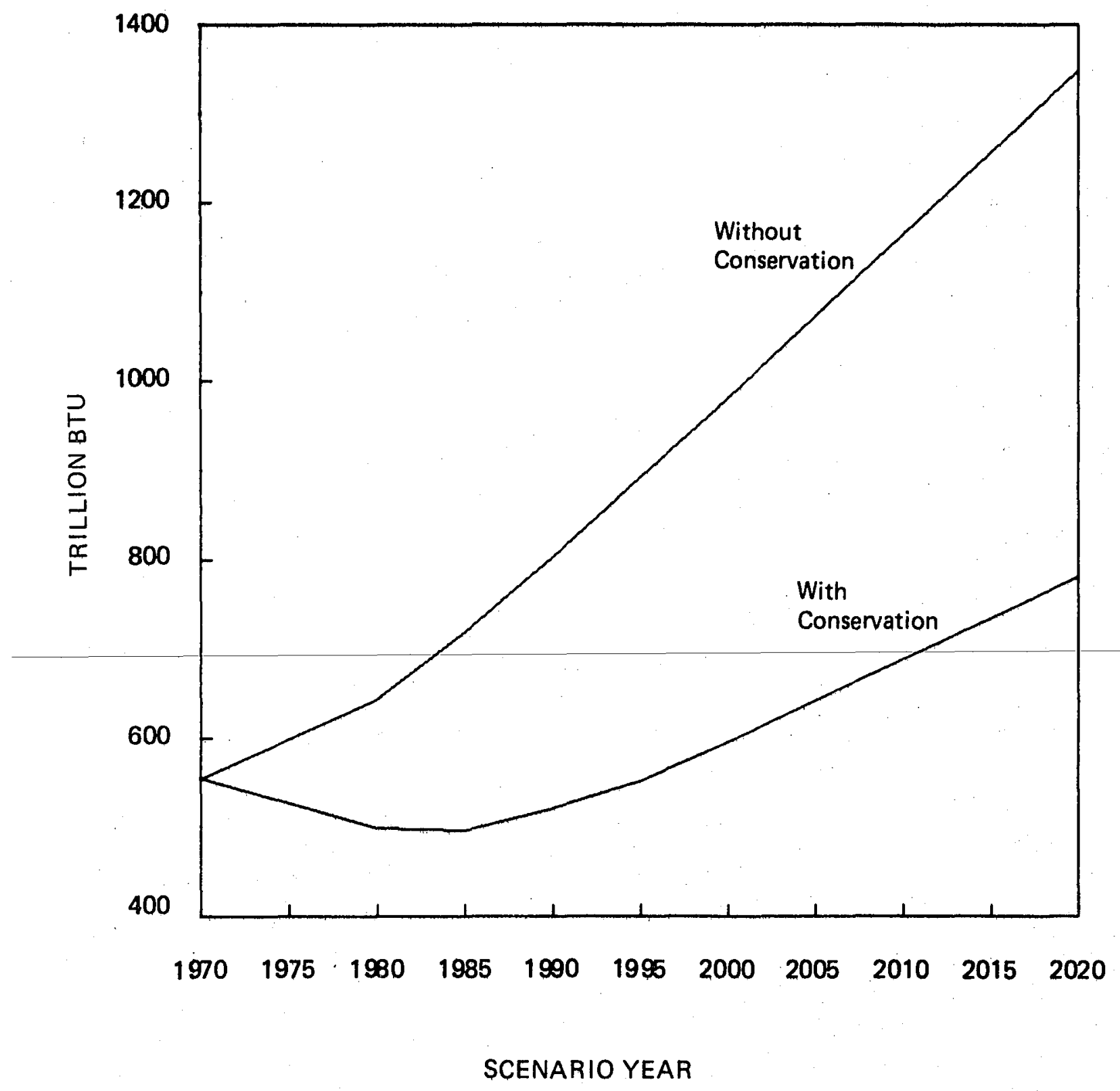

Figure 2. Commercial Sector Energy Consumption. 


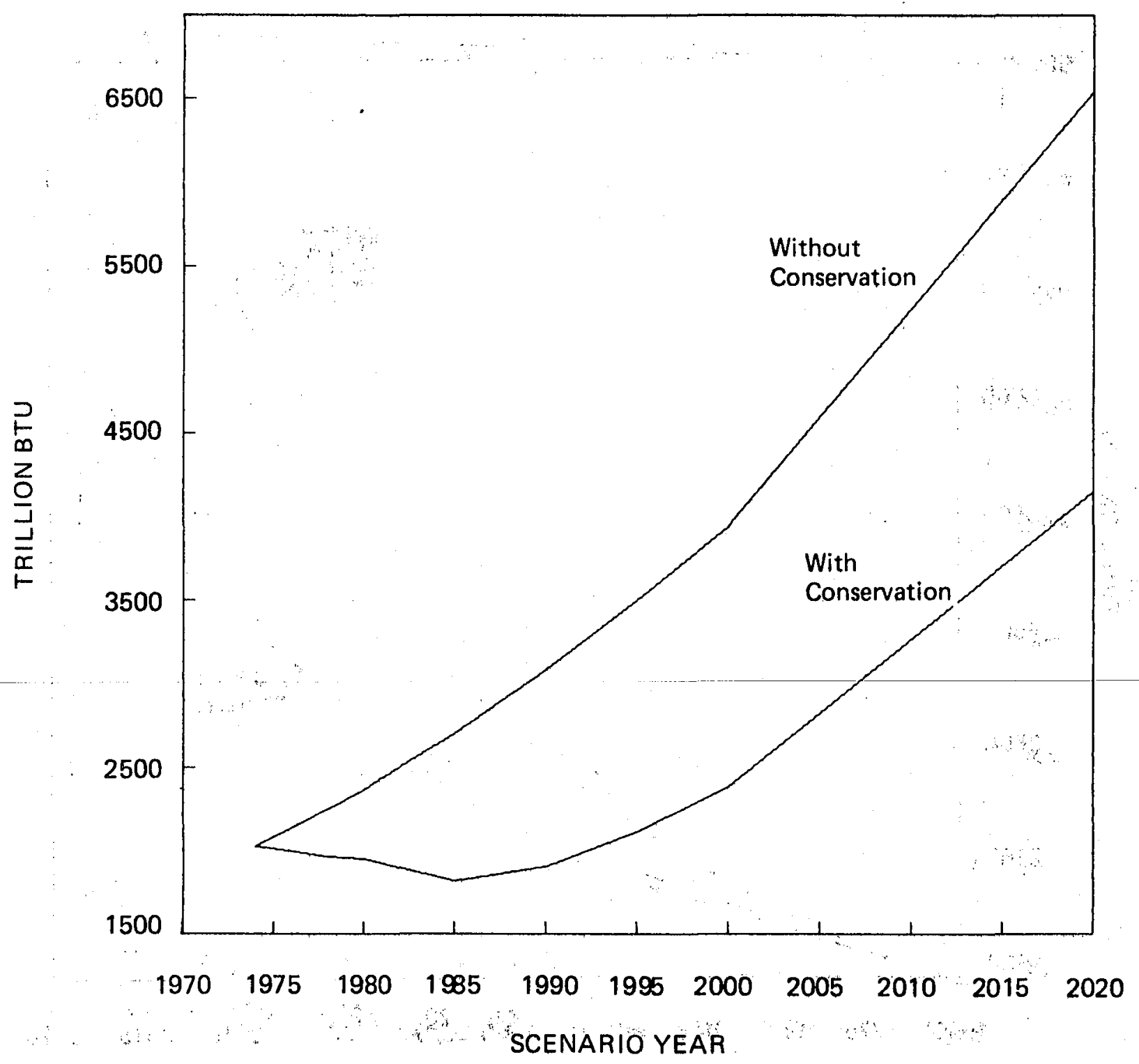

Figure 3. Transportation Sector Energy Consumption 


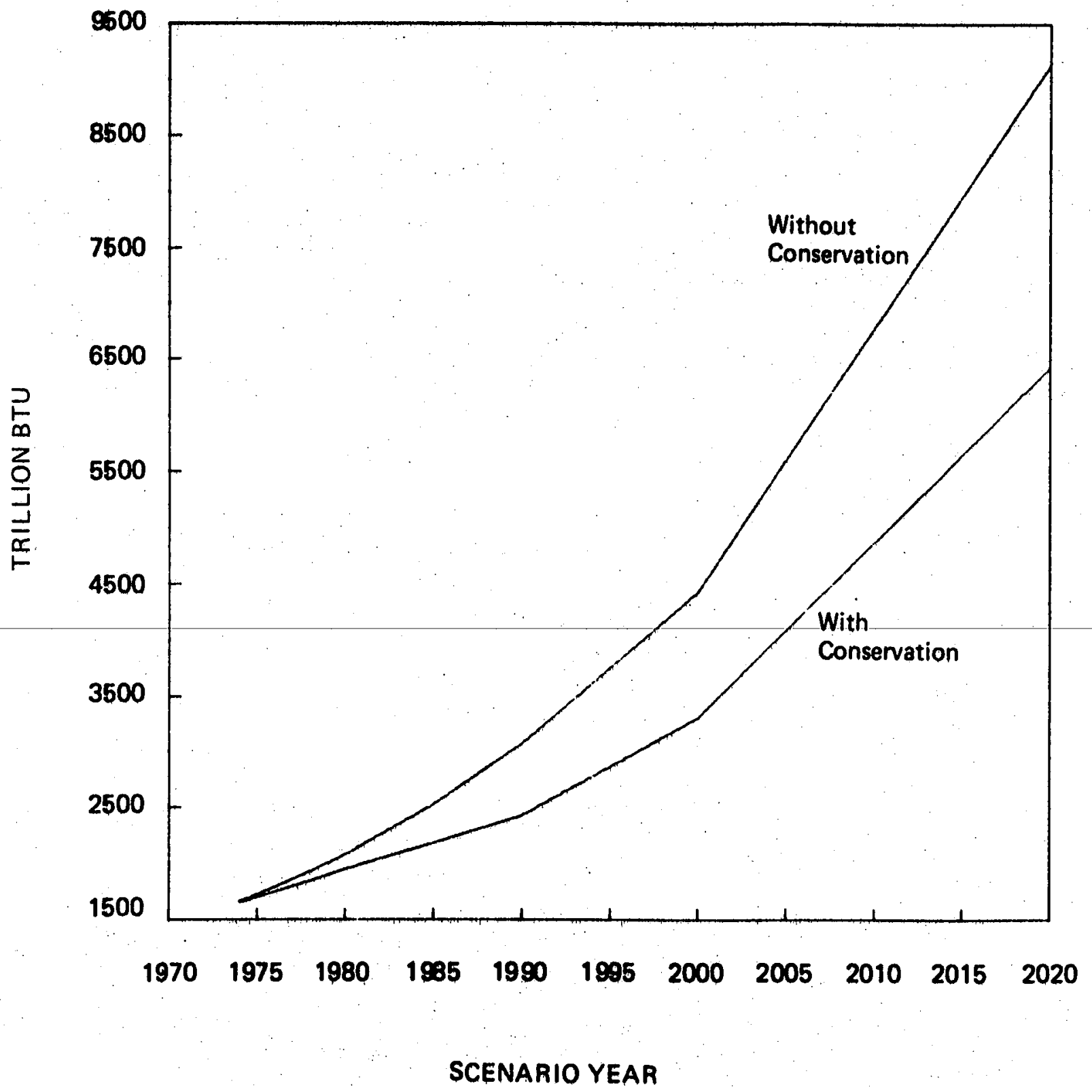

Figure 4. Industrial Sector Energy Consumption.

(3.34\%/capita/year growth in value of industry shipments.) 


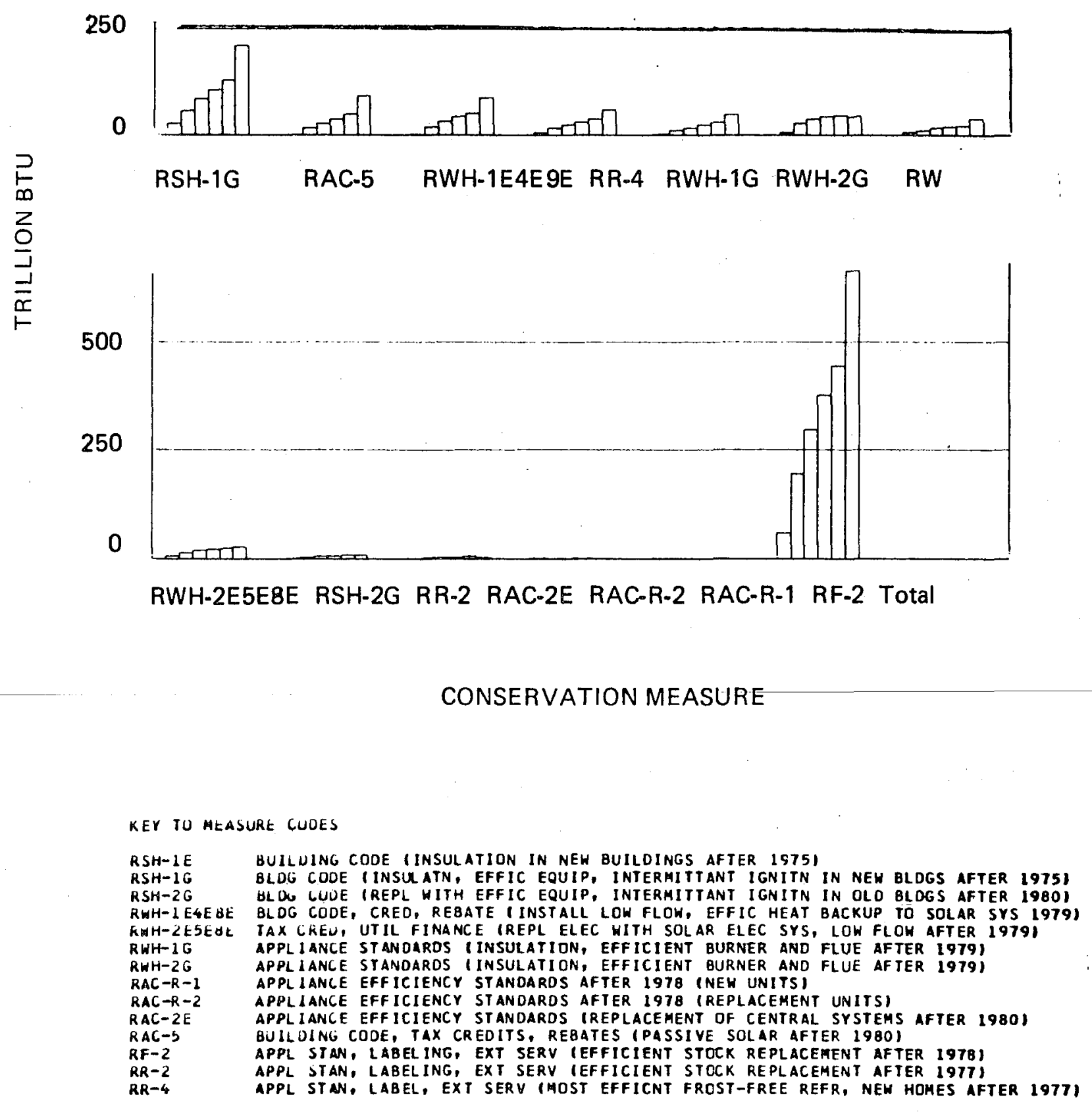

Scenario Years: 1980, 1985, 1990, 1995, 2000, 2020.

Figure 5. Residential Sector Energy Savings. 


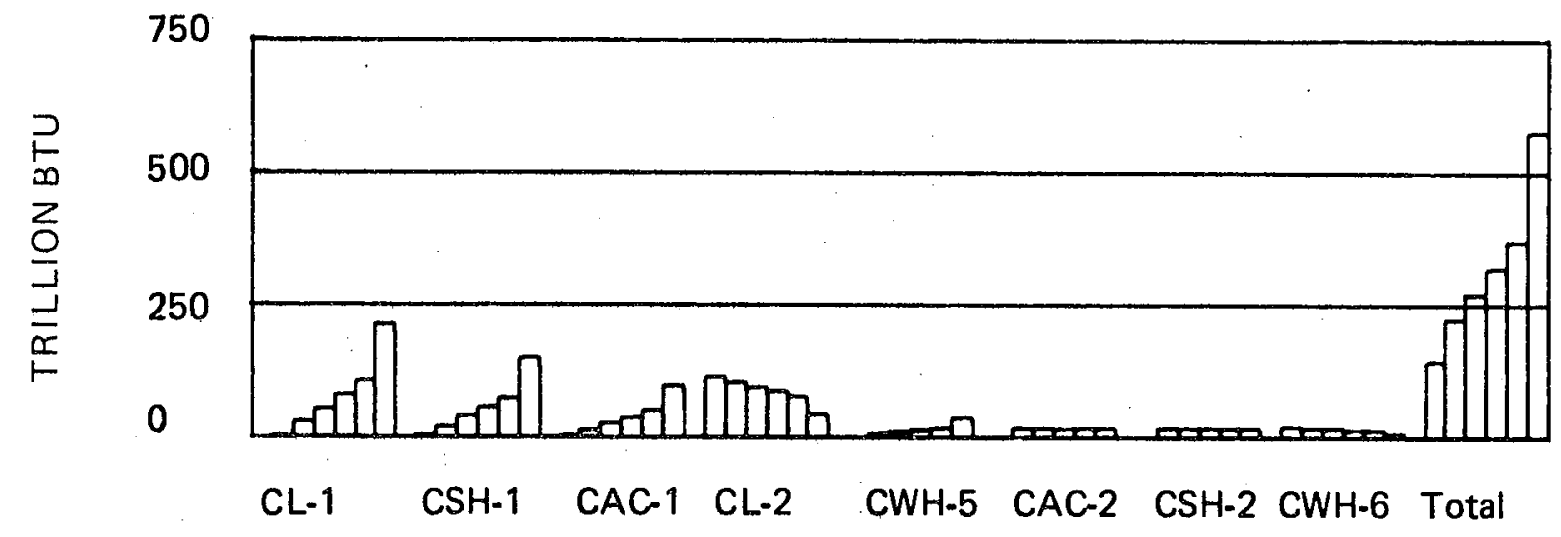

CONSERVATION MEASURE

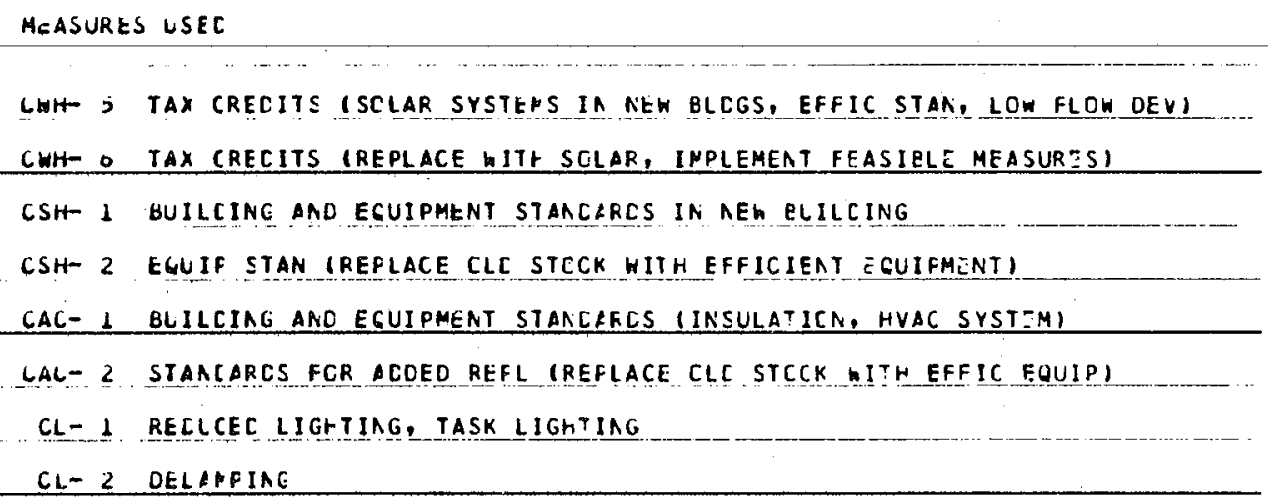

Scenario Years: 1980, 1985, 1990, 1995, 2000, 2020.

Figure 6. Commercial Sector Energy Savings. 

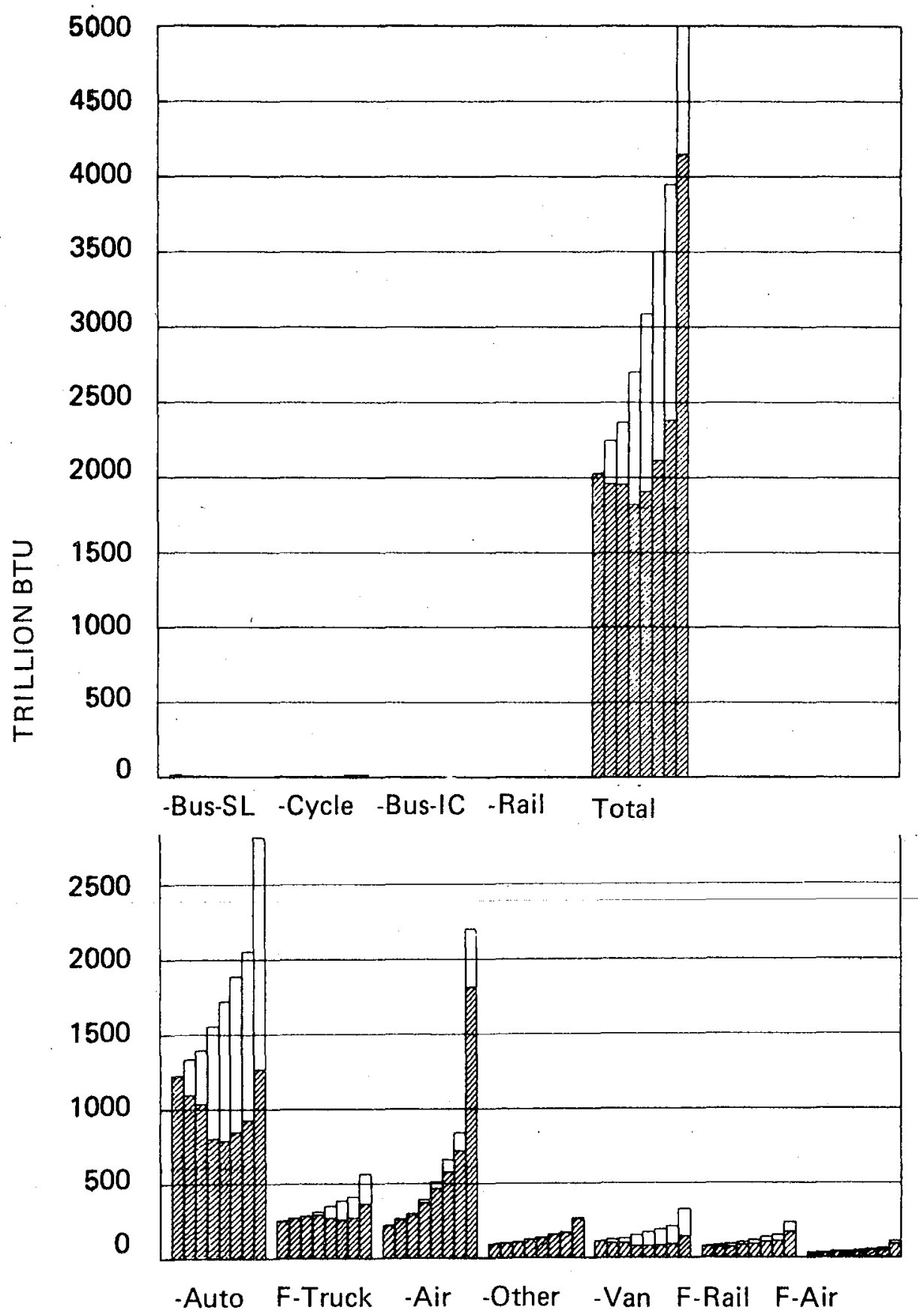

\section{MODE}

Scenario Years: 1974, 1978, 1980, 1985, 1990, 2000, 2020.

$$
\begin{aligned}
& \text { F - Freight } \\
& \text { IC - Intercity } \\
& S L \text { - School and Local }
\end{aligned}
$$

Figure 7. Transportation Sector Energy Consumption. 

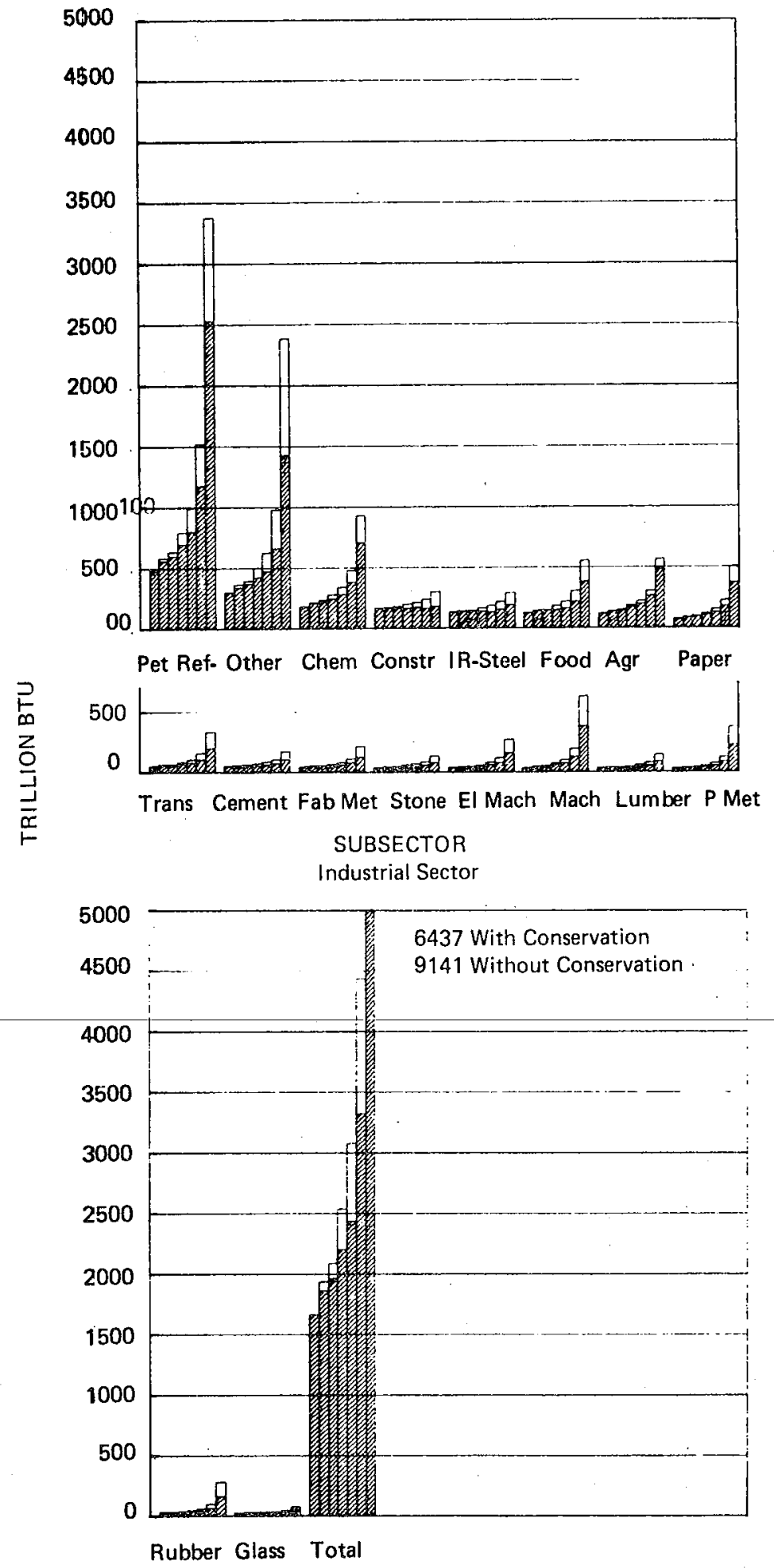

SUBSECTOR

Figure 8. Industrial Sector Energy Consumption.

Scenario Years: 1974, 1978, 1980, 1985, 1990, 2000, 2020. 
highest absolute savings. These exceptions are only tentative, however, because the full conservation potential for any enduse has not yet been estimated--implementation of additional measures would change the conservation potential and could alter the relative amounts of saving of some end uses. This is particularly true of the transportation sector. The level of government (local, state, or national) at which conservation policies can be implemented varies with the transportation modes and measures in question. Some measures, such as encouragement of carpooling, are amenable to state and local government action; others, such as rail and airplane efficiency standards, are not. Thus caution is required in the calculation of transportation energy conservation potential.

The transportation scenario highlights the role of a few conservation measures that reduce automobile energy consumption. The improved heat engine, combined with smaller,more light weight cars and reduced travel speeds yield a cumulative energy savings, when fully implemented, of approximately $55 \%$ of the total automobile energy consumption. With the exception of reduced travel speed, these savings are prorated in proportion to the percentage of travel in new cars that have the design improvements. Because automobile energy consumption accounts for approximately $60 \%$ of the total California transportaion energy consumption, this change strongly decreases annual energy consumption. The initial decrease in estimated transportation energy consumption reflects this impact.

The conservation measures for the residential scenario are ranked in descending order of savings attained in 2020 . The largest savings are realized in space heating, the enduse in which the most energy is consumed in all scenario years in both cases. Presently natural gas is the major energy source for space heating; the conservation measure that reduces gas used for space heating (RSH-1-G), is consequently the largest energy saver. Passive solar housing $(R A C-5)$ ranks second because of the energy savings from air conditioning in the later scenario years. Generally measures that affect new stocks result in larger overall savings than the corresponding retrofit measures because of the relative importance of new stocks over existing stocks.

Of the measures applied to the commercial sector, the two measures resulting in the largest savings are, first, downwatting and task lighting, followed by more efficient heating and cooling systems combined with better insulated building envelopes. Measures that affect new building stocks result in larger absolute savings than comparable measures affecting existing stocks; savings from the latter measures peak relatively early and then decline over time as existing stocks diminsih. This early peak produces a decline in the estimated commercial energy consumption 
curve before the eventual upward trend begins. Between fifty-six and ninety-one percent of the savings from each measure occur in retail-wholesale, miscellaneous, and of fice buildings. A conservation strategy in the commercial sector directed toward these three building types has the potential for yielding large energy savings.

In the commercial sector, the effect of climate on energy savings can be shown by comparing space heating conservation potential for new building stock in northern with southern California. Even though for all building types, the floor space in southern California is almost double that of northern California, the savings potential connected with space heating for retail-wholesale buildings in northern California is only $13 \%$ less than the savings for this building type in southern California. For the next major building type--Miscellaneous--northern California savings exceed the corresponding southern California savings by $12 \%$. These results reflect the higher energy intensities for space heating of northern California commercial buildings compared to the same building types in the southern part of the state.

\footnotetext{
The data upon which the graphs and discussion are based are presented in tabular form in the main report and its appendices. For each sector the tables for a base and conservation secnario are included. The resulting scenarios indicate the energy consumption by end use, fuel type, transportation mode, industrial subsector and utility service areas that can be aggregated into two climate zones (northern and southern California) permitting application to many other areas of the United States. The scenarios are not intended to provide point estimates of energy consumption in a particular year, but rather to contrast two conditional consumption scenarios and evaluate the potential savings due to energy conservation.
} 
This report was done with support from the Department of Energy. Any conclusions or opinions expressed in this report represent solely those of the author(s) and not necessarily those of The Regents of the University of California, the Lawrence Berkeley Laboratory or the Department of Energy. 
TECHNICAL INFORMA ION DIIVISION LAWRENCE BERKELEY LABORATORY UNIVERSITY OF CALIFORNIA BERKELEY, CALIFORNIA 94720 